\title{
Study on the Aesthetic Flexion of Clowns
}

\author{
Qiumin Chen ${ }^{1, *}$ \\ ${ }^{1}$ Communication University of China, Bejing, China \\ *Corresponding author. Email: baobao452370@qq.com
}

\begin{abstract}
Clowns are an indispensable role type in literature and drama. Unlike the upright heroes, clowns tend to be placed in subtle places such as the margins of the main story line. As a result, the aesthetic process of clowns is more complicated. This paper puts forward the aesthetic "flexion" of clowns, aiming to reveal this seemingly insignificant role type yet with complex and rich features, and expounds from four aspects: concealment, the particularity of female clowns, the internal correlation between ugliness and "fear", and the internal correlation between ugliness and "sadness". Finally, it extends to the important role of clowns in existentialism.
\end{abstract}

Keywords: Clown, Comedy, Flexion, Female, Fear, Absurdity, Sadness.

\section{INTRODUCTION}

In drama, literature and art, stories require many types of characters. While in Western drama there are protagonists, villains, followers, and mistresses and so on, in Chinese opera, there are some fixed roles: Sheng, Dan, Jing, Mo, Chou. The audience often focus on the fierce conflict between the main character and the villain, but the many seemingly insignificant clowns in the play usually run through the play in a gagging and laughing way, carrying huge energy. However, since the aesthetic features of clowns are concealed and covered, it is necessary to peel off layers of appearance to reach their inner nature. The clowns are often the full stop that reveals the profound philosophy of the play. This paper puts forward the "flexion" of the aesthetic characteristics of the clowns in order to explain the factors which are difficult to penetrate included by the aesthetic characteristics of clowns.

\section{THE CONCEALMENT OF CLOWNS IN THE STORY}

A "clown" is a drama-literary concept, one of several types of characters that are divided according to their function. The concept of clowns can be found in any art form that has a story component, such as literature, drama, film and TV programs, sketch and other artistic categories. And the very word "drama" has different meanings in different cultures: The word "clown" in the context of Western dramaturgy usually refers to some wacky and funny characters in a show. Clowns can appear in any type of play, more commonly in comedies. In the context of Chinese opera, "clowns" is a very clear concept, which refers to the "Chou" among the five categories of traditional opera stylized performance: "Sheng (the male character type in Beijing opera, etc. ), Dan (the female character type in Beijing opera), Jing (the "painted face", a character type in Beijing opera with a painted face, etc.), Mo (a traditional opera character, usually a middle-aged or older man) and Chou (clown in Beijing opera, etc.)". What this paper is going to discuss is the clowns as a whole of narrative art.

While the clowns in western dramas do not have a uniform pattern, the "trade" of Chinese operas is strictly standardized. The stage make-up of clowns, for example, is usually distinguished by the face covered with white powder - "A facial makeup that features putting white powder on the face is called 'Malian'. " " According to the scope of facial makeup, Malian is roughly divided into the three categories of "tofu face" "kidney face" "date pit face". In terms of functional classification, clowns are further divided into "Wen Chou" (often plays the role of playboy, jailer, bartender, watchman, veteran and so on), "Wu Chou" (often

Liu Si. Clowns (Roles and Characters of Chinese Opera), Tianjin: Baihua Literature and Art Publishing House, 2013, P23. 
some clever and funny characters with superb martial arts), "Fangjin Chou" (mainly playing the role of literati wearing a scarf on the head) and special female clowns — "Chou Dan" (the female clown). Of course, the latter two basically fall to the category of "Wen Chou". Clowns have varied stage skills. "Because the characters they play in the operas are people from all walks of life, they have to speak a variety of dialects in addition to Jing Bai (parts in Beijing opera spoken in Beijing dialect)", "some clowns have to act in a dispirited or weird manner" 2 , or some can even "play dwarf". From the perspective of the plot, clowns usually serve as the "helpers" of the main characters — servants, peddlers, messengers and laborers - in addition to the interludes at the beginning of the play, and they have to pick up the conversation from the main characters (with inherent connection with "Peng Gen", which refers to helping the leading role make the audience laugh with words or expressions in cross-talk). There can be many clowns in a play, most of which just show up and exeunt.

As is often said, every hero has a clown by his side. It is true, like Pigsy who carries the load, Harry Potter's hapless sidekick, Ron Weasley, as well as Don Quixote's servant, etc. The "hero/protagonist-clown/attendant" structure is concealed. For a moment, the audience seems to notice only the main characters, while the clowns seem to be not indispensable, at best as a tool man to control the progress of the story, or to make the audience a little impatient. But thinking it over, one can see that there wouldn't be tall and valiant heroes without the clowns.

No matter in what kind of cultural background clowns are usually characterized aesthetically by "bantering", "teasing", "funny" and "laughing" features. They usually serve to gag, adjust the rhythm of the story and ease the audience's mood in the play. Compared to other types of characters, clowns are often sidelined from the main story line - the plot is well acceptable without them, and better with their embellishment. Clowns are usually gross, frivolous, brusque, stupid, or indomitable. But we should not taste clowns simply as funny tool men, as the value of the flexion in clowns deserves extra attention: in many cases, there are two or three inflection points in the aesthetic process for clowns - the appreciation of them is not as straightforward and easy as that of other role

2 Liu Si. Clowns (Roles and Characters of Chinese Opera), Tianjin: Baihua Literature and Art Publishing House, 2013, P6. types and sometimes they are even more complex than the main characters.

The word "flexion" is used in physics to describe the phenomenon of refraction. Light flexes in water, so that what one sees above the water is not the true position of something under the water. A chopstick stuck in the water, for example, appears to have broken at the surface. Flexion suggests that there is - and this may not be what it seems - some kind of break between reality and representation. The image of the clown is just that: it seems barbaric, shrewd, and not presentable, but with their presence the other characters seem more obvious - the qualities of righteousness and evil come to light and the themes of love and life abound. But it is the flexion of the clowns that suggests to the audience that the straight-talking characters are only the product of sober reason, the representation of ideals; and the clowns, who hide in the dark corners, reveal the potential aspects of the soul - other types of roles can only be considered as a complete human nature when they are combined with clowns. Stephen Chow's films, for example, often feature some unkempt and bedraggled characters in their middle age or above who stumble into conversation between the main characters, or who suddenly rush in and cause a riot. Such scene seems bothersome, but can provide a kind of profound aftertaste later.

\section{THE REASON WHY THERE ARE FEW FEMALE CLOWNS}

Clowns are often male figures, although there are no accurate statistics, but it is roughly estimated that the number of male clowns should be at least 10 times more than that of women. Classic male clowns are numerous, and the popular female clowns such as grandmother Liu in "A Dream of Red Mansions", the matchmakers and maids in Chinese opera and so on. This reflects the hindrance to the aesthetic process of character images from a kind of stereotype.

Dramatic role is a kind of comprehensive product that contains social, ideological and artistic attributes. Therefore, a dramatic role should be consistent with the truth of life, and yet different from it. In traditional Chinese opera, "Chou Dan" is also called "Cai Dan", and since "Chou Dan" is female in the opera, they don't eat 'kidney', 'tofu', nor do they hold 'date pit' in their mouth; but 
they've got their faces." ${ }^{3}$ Sometimes they are heavily made up with rouge on their face, and sometimes they have a large mole on the corners of their mouths, very different from the usual moles. In film and television plays, the dressing of female clowns is not so prominent, just not as refined and elegant as the heroine. So, the category of "beauty" stands out here. The social ideology has made strict requirements for the "beautiful" attribute of female appearance historically, while society's expectations of men are broader: they can be beautiful, powerful, funny, or uninhibited. It is best for a woman to be either sexy or demure, either in a sub-category of "beauty". Accordingly, it's risky to have a female character take on the "playful" or "funny" task. If this is to be done, the dramatic tension on her body must be able to counteract the audience's selfcontained "gender gaze", which will be very difficult for the creator. Therefore, the story script uses a fixed and rigid social perspective to construct the characters, which is indeed based on the principle of typicality. Therefore, the aesthetic process of female clowns is more flexional: the audience needs to actively change the fixed social framework in their mind, and then observe and examine them after revising the predetermined aesthetic expectation.

The "ugliness" of "clowns" ("Chou Jue" in Chinese, literally means "ugly roles") should not only be the "ugliness" in contrast to beauty, but should be a grander abstract concept, which can be associated with such aesthetic categories as "absurdity", "irony" and "sadness". For example, in Yang Miaozhen, the female crown in "The Peony Pavilion", the "ugliness" in contrast to beauty can hardly be felt, while the "strength" and "rebellion" are somewhat reflected. Her "ugliness" is closer to a form of "profile" — a silhouette of a trait rather than a fixed model of a stereotype. The audience's aesthetic view of female clowns should be more fluid rather than in an either-or way. It is another key to the aesthetic flexion of clowns to get rid of the established social identity.

\section{WESTERN POP CULTURE: COULROPHOBIA}

The image of the comic character has an extreme type - the clown. Clowns are a common sight in Western pop culture, popping up in carnival venues and children's playgrounds, etc. Clowns,

Liu Si. Clowns (Roles and Characters of Chinese Opera), Tianjin: Baihua Literature and Art Publishing House, 2013, P23. usually dressed in colorful clothes with a round red nose, were originally created as comic figures to entertain audiences, but in recent years they have developed into a horror element in American folk culture, even giving rise to the concept of "Coulrophobia". How did clowns go from being funny to being evil and scary?

In appearance, clowns are similar to the combination of the "Jing" and "Chou" of Chinese opera: with exaggerated colors covering the body, and towering hat and conspicuous clothing and adornment...they were clearly meant to be funny. Clowns break the strenuously constructed daily norms, the order of conformity, and the positive momentum. They drive the audience to relax by making a mess. Therefore, there is a profession called "clown therapists" in European and American countries who perform for patients suffering from mental anxiety and children with autism, in order to achieve the therapeutic effect.

But clowns just got creepier and creepier somewhere along the line. With all that colorful appearance and exaggerated and grotesque styling, they look more like something between human and monster than our kind. This idea has spawned film characters such as Jangles ("Figure 1"), the clown who lives in the unconscious realm of the hero in "Inside Out", and the Joker who kidnaps children in "The Joker" ("Figure 2"), etc. They are all in the category of "horror" already in terms of appearance.

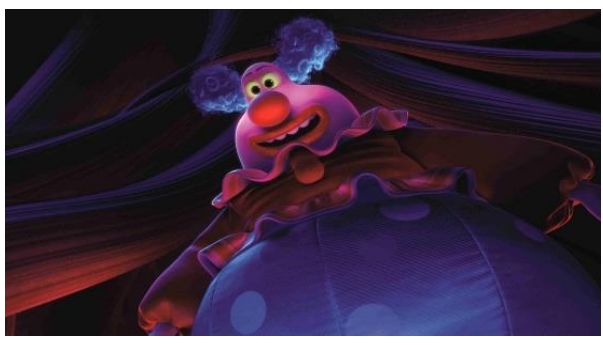

Figure 1 Jangles in "Inside Out".

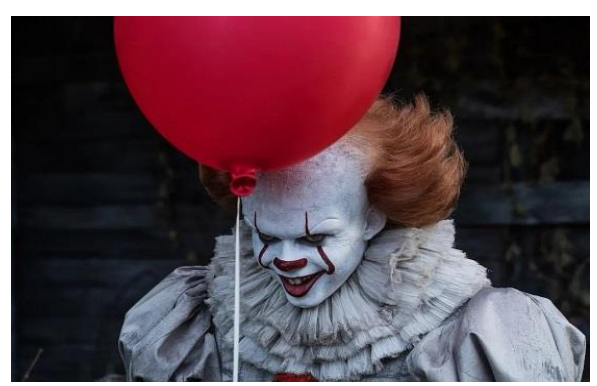

Figure 2 Pennywise in "The Joker". 
Pennywise in "The Joker" is always hiding in a dark sewer, waiting for a chance to abduct children, most of who die in the end. The trick to defeating him is to laugh - laugh loudly, and it will weaken and shrink; and if you fear it, it will manipulate and kill you. There is a metaphor in this story: the clown is always hiding in the dark; something we want to ignore it, and the more we try to do this, the more dangerous the subconscious is. The fear of clowns stems from our own helplessness, which is the will of slaves. Therefore, in the face of Pennywise one cannot use the iron fist, as force will only make it more powerful. And only when one ignores him from the bottom of the heart and override it, will it collapse itself. There is also a kind of flexion in this: the use of comical, disorderly channels for a laugh and a moment of relief is supposed to be a means of healing and repair, but after relaxation comes the greater abyss - the truth of life and the of existence. There's a no-direct viewing logic to this: Why do clowns' therapeutic function and scary images always work for young children? It is because young children often do not develop the complex ability to distinguish between appearance and essence, mainly act according to instinct, and often rely on the automatic mechanism of instinct when they encounter setbacks and dangers, thus lacking the initiative of strong will mentioned by Nietzsche. The aesthetic principle of clowns is to rebel against the order and break the peace, but this just reminds people that they can not only stay at this level, but also need active and motile reflection and metaphysical contemplation in order to get the real spiritual repair.

It can be seen that the "fear" over clowns is different from the fear for the sublime and the hatred of the evil. It is actually a harmless psychological situation, and the fear of the internality of the deliberately hidden self. Although the "ugliness" of clowns is different from the "ugliness" in contrary to beauty and "evil", they are also intrinsically related. Both of them have the property of rebelling against harmony and order, the difference is that "evil" is to destroy things completely, while "ugliness" is just a harmless warning.

\section{IT IS THE SAD CORE OF CLOWNS BEHIND LAUGHTER}

Another prominent aesthetic feature of clowns is "banter" and "laughter". So it is worth investigating the causes of laughter and the various factors that may trigger the mechanism of laughter. There are several possible reasons for laughter: itchy physical stimulation, emotional pleasure, funny object, and sarcasm. Most of the laughter that comedies bring is in the latter two situations. A mechanism by which the clowns, who are often responsible for making people "laugh," evoke laughter or ridicule in the audience by some special means — "There seems to be a direct correlation between the extravagant feeling that things that are 'whimsical' and 'fantastic' in the realm of ideas and tastes evoke and the particularity that is laughable because it is so far removed from the general ways of life. ${ }^{4}$ "Funny laughter involves a kind of sidelining fun — we laugh at things that don't conform to our conventional wisdom, and we think we're acting in a legitimate way. Although this kind of fun is harmless, it has more or less contained the "evil" in human nature. A sardonic laughter is a way of looking down from above - look, he's made a fool of himself, and I haven't. This is also a harmless "evil". As a result, clowns are often vulgar, old, clumsy and dull little people, who exist just to break away from the image of the elite and the upper class.

So there is a close relationship between the aesthetic process of clowns and the negative emotions. Clowns reveal all kinds of embarrassment, indecency and mess in life. In all kinds of coarse and bantering plots, people feel the authenticity of life and feel a kind of warmth where they no longer need to calm down or pretend. Behind the images of freaks, wretches and ruffians are often more complex social backgrounds, or tragic life stories, or indescribable difficulties, which the author does not put all on the table. And these hidden things are more heavy tragedy of fate and society. Therefore, the seemingly funny characters often reveal the essence of existence in a deeper way - life is already suffering, but the sadness of the existence has to be distorted and then presented to others in a way of laughter, which is the predicament of existentialism.

Humans often dream, creating all kinds of beautiful illusions to compensate for unsatisfied desires and inhibitions. The human ability to dream is not limited to dreams during sleep - the exaggerated packaging of goods, the fancy atmosphere of social situations, the cult of celebrity worship...Wise people take advantage of

(UK) Sully, James. An Essay on Laughter: Its Forms, Its Causes, Its Development and Its Value. Beijing: China Social Sciences Press, 2011, P76. 
psychedelic beauty as bait, and the masses, who are born suffering, empty their wallets yet enjoy themselves. But they have not been substantially satisfied. Clowns often break the illusion of beauty in unexpected ways - they break into people's subconscious zones and cause riots, bringing viewers straight to the tragedy of existence. If philosophies do this, the difference between them and comedies and clowns is the way and the method: while the former is rational and intuitive to actively deal with various dilemmas, the clowns appear in an unexpected way, showing people as "funny" images with the aesthetic flexion, and then revealing the original dilemmas of existence. Very often, it has been revealed, but people are not even aware of it. Although different artistic methods (and philosophical methods) ultimately achieve infinite externality, and the same is true of the clowns as the aesthetics of the clowns should finally reach the metaphysical contemplation, we can still dig more into the particularity, surprise, fun and rebellion of the clowns.

If the protagonist brings audience the straightforward experience with ups and downs, the experience brought by clowns, on the other hand, is meandering, a little odd at first but not too flavorful, leaving a lingering aftertaste after being thought over carefully. The aesthetic "flexion" of clowns is usually born from the creator's deep consciousness and collective unconsciousness. In creating the characters of clowns, the author often exerts unconscious impulses that he is not even aware of. Various images of clowns are highly condensed, and instead being just frivolous funny condiments, they have a distant, deep sobriety. The image of the clowns is often ironic, as their "silliness" and " frivolity" is more like playing possum and feigning madness, and they seem to choose to be an onlooker. But behind this is the vast loneliness and bitterness. In the process of being created, these clowns may not be designed and assembled by the author one by one, but may come more from the deep consciousness left by the creator's life experience and the artist's keen capture of the collective unconscious experience of human beings. Or that the spontaneous response of humans (and other beings) to the outside world is inherently tragic, and that externalizing it through flexion and sinuous means is an exercise of strong will.

This reflects what people call "the essence of comedy is tragedy". Whenever there is profound value, be it in a comedy or a tragedy, their theme is usually deep in the contemplation of existentialism — the root of "sadness" comes from the common survival dilemma of human beings. It's hard to imagine 100 percent pure laughter and hilariousness in the adult world. And the main function of art is to capture these delicate emotions with precision.

\section{CONCLUSION}

The symbolic meaning of the clown is of higher value than the practical meaning, that is to say, the clown is a symbol in the drama, which bears some specific functions in the overall structure of a play. If the protagonist is the ideal and model after refinement, the clown is the timid, selfish and selfdeprecating side of the abstract human character. Therefore, the core of a play's sadness is usually manifested in the main character, but is fulfilled in the clowns. Thus when appreciating clowns, one should realize the inflexibility of their aesthetic logic, and peel off layers and dig deeper so as to have a more diverse and richer understanding of the plays.

\section{AUTHORS' CONTRIBUTIONS}

This paper is independently completed by Qiumin Chen.

\section{REFERENCES}

[1] Wang Zheng. History of the Motif of Chinese Classical Drama. Beijing: China Social Sciences Press, 2015. (in Chinese)

[2] Zou Yuanjiang. Lectures on the Whys and Wherefores of Drama. Hunan: Hunan Education Publishing House, 2007. (in Chinese)

[3] Jiang Jurong. Collection of Studies on Tang Xianzu. Shanghai: Shanghai People's Publishing House, 2015. (in Chinese)

[4] Jia Zhigang. Theories and Criticism of Drama. Beijing: China Federation of Literary and Art Circles Publishing Corporation, 2015. (in Chinese)

[5] Liu Si. Clowns (Roles and Characters of Chinese Opera), Tianjin: Baihua Literature and Art Publishing House, 2013. (in Chinese)

[6] (UK) Sully, James. An Essay on Laughter: Its Forms, Its Causes, Its Development and Its Value. Beijing: China Social Sciences Press, 2011. 
[7] (US) Helitzer. Comedy Writing Secrets. Nanjing: Nanjing University Press, 2003.

[8] (Germany) Peter Szondi. Theorie of Modern Dramas (1880-1950). Beijing: Peking University Press, 2006. 